\title{
Escravos e Abolicionismo na Imprensa Mineira (1850-1888)
}

\section{Liana Maria Reis}

O presente trabalho constitui a primeira etapa de um projeto de pesquisa ${ }^{1}$ cujo tema é a atuação política dos escravos entendida como toda manifestação do cativo ('pacífica' ou 'violenta') no sentido de fazer frente às relações de dominação sob as quais estava submetido expressa tanto nas ações praticadas dentro dos espaços institucionais (legais), abertos pelo sistema escravista, como nos diversos atos de rebeldia referidos nos inúmeros jornais do período de 1850 a 1888 , na província de Minas Gerais. $^{2}$

$\mathrm{O}$ recorte temporal não foi estabelecido aleatoriamente. $\mathrm{O}$ ano de 1850 marca o fim do tráfico negreiro e este fato vai interferir, de forma significativa, nas transações das relações sociais (especialmente na relação senhor-escravo), na medida em que as discussōes acerca da continuidade da escravidão e a busca de solução para o problema da mão-de-obra tornavam-se inadiáveis para os proprietários escravistas. Por outro lado, este fato implicou provavelmente na abertura de novas possibilidades de negociação política por parte dos escravos na conquista de certos direitos, pois os proprietários passaram a se preocupar com a manutenção da força de trabalho assegurando a continuidade dos seus investimentos; haja vista o aumento dos preços dos cativos e os limites impostos pelo tráfico interprovincial. Estes fatos podem explicar, pelo menos em parte, o "melhor tratamento" dispensado aos cativos nos anos posteriores a $1850 .^{3}$

$\mathrm{O}$ ano de 1888 marca outro momento significativo do processo histórico brasileiro com a extinção jurídica da escravidão. A Lei Áurea, 
de 13 de maio, é percebida como expressão da dinâmica social, ou seja, como resultado de acordos e confrontos cotidianos travados entre os sujeitos históricos. Sendo a lei o "principal veículo para o exercício de hegemonia pela classe dominante", ${ }^{4}$ ela vai interferir também nesta dinâmica, regulando, transformando e limitando juridicamente a ação política destes mesmos agentes sociais. ${ }^{5}$ Portanto, os marcos 1850 e 1888 não são entendidos como simples datas ou eventos, mas se inserem num contexto mais amplo no qual representam apenas momentos conjunturais daquele processo histórico.

Privilegiamos Minas Gerais, dentre outros fatores, por ser a província que congregou o maior plantel escravista do país, ${ }^{6}$ tendo um desenvolvimento específico deferenciado das demais economias regionais brasileiras, como uma base produtiva muito diversificada e a predominância de pequena e média posse de escravos, ${ }^{7}$ o que ampliou a base social de sustentação do próprio sistema escravista.

A opção em trabalhar com jornais, enquanto documento básico, se justifica na medida em que eles se constituem fonte histórica extremamente complexa, na qual podemos perceber a convergência de opiniōes e visões de mundo diversas, representativas daquela sociedade. Neste sentido, o jornal tornou-se um importante veículo de comunicação, divulgador de ideologias (escravista, abolicionista, etc.), utilizado como relevante mecanismo de controle social, como por exemplo, ao tornarem públicas as condições de fuga e descrições físicas do escravo fugido facilitando sua localização e conseqüente aprisionamento.

Sem dúvida, a imprensa é um "manancial dos mais férteis para o conhecimento do passado"s e hoje os jornais são reconhecidos como importante fonte de estudo de uma dada realidade. Contudo, como quaisquer outros documentos, os jornais são representações do real produzidos por indivíduos historicamente condicionados e portanto não são isentos de subjetividade. Para utilizá-los como fonte de pesquisa cumpre identificar por quem e quando foram produzidos, com quais objetivos e para atender a que tipo de leitores e interesses, pois que "sua existência é fruto de determinadas práticas sociais" de um tempo. ${ }^{9}$ Nesta perspectiva, nossa postura diante dos jornais será de apreendê-los não enquanto "verdades" de uma realidade histórica ou como veículo imparcial de transmissão de informaçōes, "mas antes como uma das maneiras como segmento localizados e relevantes da sociedade produ- 
ziram, refletiram e representavam percepções e valores da época". ${ }^{10}$ Procederemos a uma certa leitura dos dados identificando os sinais, resquícios e fragmentos do passado, que associados à "intuição" do historiador permitem captar nas entrelinhas do documento básico o "não dito", a fala silenciada, representações e percepções nem sempre explicitadas mas perceptíveis que informam múltiplas visões dos vários aspectos da sociedade. Se é certo que não se pode conhecer, explicar e reconstituir a complexidade do real vivido - a totalidade de uma dada realidade histórica - podemos nos aproximar do "real" atentando para detalhes a priori desprezíveis mas que podem "revelar profundos e significantes fenômenos". Como nos ensina Carlo Ginzburg: "A realidade é opaca: mas há certos pontos - pistas e sinais - que nos permitem decifrá-la". ${ }^{11}$

O estudo visa, pela análise dos dados, reconstituir historicamente as relações sociais estabelecidas entre escravos, senhores, forros e homens pobres livres através de importantes informações sobre a vida cotidiana do escravo, bem como as imagens construídas do cativo perceptíveis nas diversas falas dos jornais. O objetivo, num plano mais amplo, é tentar resgatar o significado histórico das várias formas de reação (como o roubo, fuga, crime, suicídio, etc.) enquanto desestabilizadoras do sistema escravista ampliando, desta forma, a compreensão da dinâmica social mineira no bojo do processo abolicionista. Neste sentido, o estudo pretende contribuir para determinar o peso político específico da rebeldia para a destruição do sistema. Num plano mais específico visamos perceber os limites históricos da atuação política, o campo de possibilidades no qual o escravo forjava estratégias de luta, surgidas do confronto cotidiano entre os sujeitos históricos.

Transcorridos mais de cem anos da extinção da escravatura no Brasil, muito pouco se sabe sobre a participação dos escravos naquele processo, particularmente no caso mineiro, o que compromete nosso entendimento acerca daquela realidade. ${ }^{12}$ Torna-se impositivo preencher esta lacuna resgatando a história de homens e mulheres trabalhadores submetidos à escravidão que no vivenciar a condição de escravos, "construíram seus modos de vida e luta", ora assumindo uma posição de submissão, ora resistindo através dos vários atos de rebeldia, bem como estabelecendo acordos e alianças no seu cotidiano. Ao estabelecerem intricadas relações com outros escravos, com senhores, homens e mulheres livres, eles construíram laços familiares, alianças, "so- 
lidariedades econômicas, culturais e sociais, que acabaram por construir uma cultura e um saber escravos - base de muitas estratégias de sobrevivência e de muitos projetos de liberdade". ${ }^{13}$ É exatamente este movimento da história que pretendemos captar no momento de desagregação do sistema escravista brasileiro - as contradições, os conflitos diários, as negociaçōes, as resistências, as alianças entre as diversas classes sociais, ${ }^{14}$ demonstrativos da divergência de interesses e comprovadores de uma realidade múltipla, diversificada e conflituosa contribuindo para a verticalização do conhecimento da história mineira oitocentista.

Tendo como objetivo central reconstituir a trajetória vivida pelo escravo, procedemos a coleta de todas as informações, que direta ou indiretamente mencionassem o "elemento servil", nos diversos jornais do século XIX das cidades mineiras..$^{15}$ Foram consultados todos os 70 títulos (de jornais da Seção "Jornais Avulsos" do A.P.M.), listados no período de 1850 a 1888 , sendo transcritos os dados de $77 \%$ dos periódicos, o que equivale aproximadamente a revisão de 4.265 exemplares. ${ }^{16}$ Os dados extraídos são extremamente ricos: são anúncios de fuga, venda, compra, aluguel de escravos, agressões, crimes; informações sobre alforrias, censos de população, e associaçōes abolicionistas, poemas, contos e discursos parlamentares, dentre outros. Podemos observar o paternalismo e o preconceito do branco expressos nas descrições das concessōes das alforrias, das fugas, dos crimes, das agressões, etc., bem como nos debates e comentários jornalísticos onde era construída uma imagem do escravo, ora visto como ser inferior - que deveria ser controlado e dirigido - ora como ser monstruoso capaz dos mais terríveis atos de barbarismo.

Os anúncios de fuga (individual e coletiva) são perticularmente detalhados ${ }^{17}$ na medida em que o senhor necessitava fornecer uma descrição física pormenorizada do escravo, seus vícios e costumes, para facilitar a identificação, localização e aprisionamento do fugitivo, permitindo ao pesquisador entender e resgatar parte da realidade do cotidiano do escravo - como as condições de vida (especialização e tarefas exercidas), o grau de exploração e violência, as perspectivas de fuga, e as estratégias criadas pelo cativo nas suas experiências diária. Em alguns anúncios aparece um dado particularmente interessante referente a uma possível ajuda (acoutamento) oferecida ao fugitivo, o que pode ser um indício da atuação de abolicionistas e/ou ajuda de outros escravos, 
forros, e demais homens livres. É ilustrativo o anúncio da fuga do escravo Marcelino pertencente a Antônio Carlos de Lima ocorrida no dia 26 de fevereiro. O dito escravo fugiu da cidade de Santa Luzia do Sabará, onde morava e a notícia foi divulgada no "Liberal Mineiro" de Ouro Preto do dia 6 de junho de 1884:

"É crioulo, alto, sem barba, terá 22 anos de idade, tem falta de dentes na frente do maxillar superior, pernas algum tanto arqueadas para dentro, pés e orelhas grandes, conserva sempre a boca aberta, fazendo-se de tolo; é porém muito esperto para correr e furtar; é pedreiro ordinário, não gosta de bebidas espirituosas e nem de café, mas é amante de doces e fuma cigarros. Seguiu d'aqui em companhia de um ex-soldado, de nome Manoel Alves (vulgo passarinho), em demanda do Curvelo, Capão Redondo, Paracatú ou S. Francisco e Januário; mas ultimamente obteve-se noticia quase certa de que ajustara para camarada de um tropeiro e seguira para Paracatú." 18

Podemos observar a estratégia criada por Marcelino (como forma de sobrevivência) como conservar "sempre a boca aberta, fazendo-se de tolo", e que foi percebida pelo proprietário que, no entanto, o julga como "muito esperto para correr e furtar" (práticas que deveriam ser comuns). Também se verifica o conhecimento que o senhor tinha dos hábitos e das preferências do escravo, inclusive no que se refere a alimentação: "é amante de doces". Fica evidenciada a participação da comunidade na localização e paradeiro de Marcelino que seguiu em companhia do ex-soldado para prováveis locais e que através de "notícia quase certa" dada ao senhor, o dito escravo se dirigiu possivelmente para Paracatu, trabalhando como tropeiro. Isto comprova que naquele momento a fuga abria possibilidades de incorporação do escravo ao mercado de trabalho livre.

Cumpre ressaltar que estes anúncios são os que aparecem em maior número no cômputo geral dos dados. A maior ou menor incidência de determinados tipos de informação são indicativos do caráter seletivo deste registro histórico (no sentido de privilegiar determinados fatos $\mathrm{e}$ informações e desconsiderar outros), devendo ter uma significação maior para aquela sociedade ou pelo menos para alguns de seus integrantes. 
As considerações expostas abaixo não são o resultado da análise da volumosa massa de documentos, mas apenas possibilidades apontadas pelos dados que indicam caminhos a serem trilhados e desvendados.

Embora todos os tipos de resistência tenham sido praticados pelos escravos ao longo dos vários séculos de desenvolvimento do sistema escravista, podemos aventar a hipótese de que, se o quilombo constituiu uma das formas mais comuns de reação escrava no século XVIII mineiro, a fuga foi a mais característica do século XIX - não excluindo outras formas de reação, nem desconsiderando que para formação do quilombo, a fuga era etapa indispensável. ${ }^{19}$

As fugas eram originadas por motivos diversos, como a separação dos familiares, os maus tratos, o simples desejo pela liberdade ou mesmo a quebra de certos acordos com os senhores, e representava uma ameaça radical ao sistema na medida em que desestruturava o processo de produção. Segundo Eduardo Silva:

"A unidade básica da resistência no sistema escravista, seu aspecto típico, foram as fugas, para um produtor direto definido como 'cativo', o abandono do trabalho é um desafio radical, um ataque frontal e deliberado ao direito de propriedade. ${ }^{20}$

Porém, se a fuga foi constante durante a vigência do sistema escravista, qual teria sido seu poder de pressão, nas últimas décadas do século XIX, no sentido de desagregar o escravismo? Segundo Ademir Gebara, dentre outros protestos,

"as fugas foram um fator de importância fundamental para forçar a precipitação final do processo de transição para o trabalho livre. Isso se daria porque, não podendo ser a fuga considerada uma atividade criminosa STRITU SENSU, ela acabaria por impor o envolvimento, de forma crescente, de setores livres da população e, com isso sua repressão passaria a depender tanto do apoio da comunidade, quanto da extensão da repressão a outros setores da população que não o escravo". ${ }^{21}$ 
Os anúncios de fuga demonstram claramente esta participação da comunidade na localização do fugitivo, ao mesmo tempo que informa a existência de laços de solidariedade entre escravos e demais indivíduos daquela comunidade. Cumpre lembrar que nos anos finais do Império a manutenção da Ordem torna-se impositiva: era necessário controlar as ações dos escravos, para garantir a continuidade da produção, e dos homens livres e forros que podiam colocar em cheque a estrutura social. ${ }^{22}$

Analisando a atuação da imprensa do Rio de Janeiro da década de 1880, especialmente os periódicos Gazeta da Tarde e Cidadão do Rio, ambos pertencentes a José do Patrocínio, Humberto Machado afirma que:

"As revoltas e fugas, tornadas mais comuns na última fase do período escravista, demonstram que os cativos não se caracterizam pela passividade, como apregoavam os defensores do regime. Por isto, era imprescindível divulgá-las." 23

Neste sentido, entendemos a importância da imprensa para a época, como veículo divulgador de idéias abolicionistas, que alertavam os senhores do perigo dos atos de rebeldia escrava, referidos como prova da inviabilidade da permanência da escravidão, e como relevante mecanismo de controle social facilitando a localização do paradeiro do fugitivo. Cabe lembrar "O Luzeiro" da cidade de Paracatu, denominado como um "periódico dedicado às avançadas", na qual se alertava:

\section{"Não se admitte Testas de FERRO e nem anúncios de FUGA DE ESCRAVOS." ${ }^{24}$}

Tal posição demonstra o conflito existente entre as diversas tendências políticas manifestado nos períodos da época, e o reconhecimento de que tais anúncios decisivamente, funcionam como um meio eficaz de manutenção do sistema. Demonstra também a importância que a imprensa e as idéias abolicionistas tiveram na formação uma ideologia que condenava a escravidão.

Entretanto, os jornais poderiam se transformar também em mecanismo de defesa do escravo fugido, na medida em que sendo o esvravo alfabetizado - como aparece em inúmeros anúncios - poderia, através 
da leitura dos periódicas. tomar consciência do grau de informação que o senhor tinha de sua localização, possibilitando o cativo procurar outras paragens.

A expansão da cafeicultura a partir de 1850 , o crescimento das cidades e a incipiente industrialização a partir da década de 70 , demandavam a montagem de uma infra-estrutura - como abertura e melhoria dos caminhos e a construção de ferrovias, como a Pedro II (1869-1889) e a Leopoldina (1874) - para facilitar o intercâmbio comercial com outras províncias e com a Corte do Rio, e para o escoamento da produção gerando empregos tanto para homens pobres livres, quanto para os escravos fugidos que poderiam passar por forros. $\mathrm{O}$ anúncio da fuga do escravo Fortunato datado de 3.8.1883 e divulgado pelo Liberal Mineiro, informa:

"[...] consta que este escravo se acha, a título livre, trabalhando na estrada de ferro entre a povoação de Soledade e Lagoa do Netto; rogão, pois, os senhores administradores ou a quem quer que seja encarragado do pagamento dos trabalhadores, que ao dito escravo Fortunato nenhum dinheiro adiantem ou paguem, antes aguardem a presença de seus senhores, com quem poderão fazer todo e qualquer contrato [...]".25

Podemos perceber a visível preocupação dos procuradores ou herdeiros da proprietária, D. Anna Amalia de Jesus, impedir a continuidade do contrato do trabalho estabelecido entre o escravo e os empregadores, feito à revelia da senhora, que não só perdera (pelo menos durante um certo tempo) aquela força de trabalho, como não tirava proveitos daquela situação.

O meio urbano abria maiores possibilidades de sobrevivência para o fugitivo particularmente se este possuísse alguma especilização, o que também aumentava as chances de negociação com o senhor, ampliando seu poder político de barganha e as possibilidades de acumulação de pecúlio para compra da alforria. Poderia ser o caso do escravo Lucindo que fugiu do sítio de Sete Lagoas, no ano de 1883, cuja fuga é anunciada no Liberal Mineiro:

"[...] é muito conversador, é muito bom oficial de pedreiro, trabalha especialmente em fornalhas de enge- 
nho de canna, é bom factor de assucar, bom lambiscador, bom ferrador de animaes, bom cavaleiro, lida muito bem com animaes, é bom cortador de rezes e matador de porcos, trabalha em diversos officios, mas é vagaroso em seu trabalho [...]."

Seria pouco provável que pelo fato de ser "vagaroso", Lucindo não conseguisse vender sua força de trabalho executando qualquer ou muitas das tarefas que tão bem sabia fazer, segundo seu próprio senhor. .

As cidades passavam, naquele momento, a constituir importantes pólos de atração de mão-de-obra, gerando por parte da classe senhorial agrária a necessidade de tentar impedir as fugas do campo - assegurando somente aos escravos que não fugissem os benefícios da lei de 1871 bem como reivindicando do Estado Imperial medidas mais repressivas contra os escravos que

\begin{abstract}
"sentindo-se garantidos pela lei e pelo fim inevitável da escravidão, fazem cada vez mais balbúrdias nas vendas e bares, em geral associados a homens livres ou colonos estrangeiros, e ameaçam a vida de seus senhores". ${ }^{27}$
\end{abstract}

O contato dos escravos com os colonos e homens livres, muitos dos quais abolicionistas e possuidores de uma mentalidade anti-escravista, contribuiu para uma maior conscientização política dos cativos. Por outro lado, ao fugir para os centros urbanos e manter relações sociais de assalariamento ou por empreitada para execução de determinadas tarefas, o escravo era aos poucos educado para enfrentar a passagem do trabalho compulsório para o livre.

Poderia haver uma estreita ligação entre aumento do número de fugas com a formação de sociedades abolicionistas? Não seriam estas associações criadas para garantir aquela passagem com o menor risco possível para a classe senhorial e demais elites políticas? Era necessário controlar o potencial de rebeldia dos escravos sem a ameaça de uma radicalização: "Era preciso mudar alguma coisa para que tudo permanecesse como antes".

Acreditamos ser possível estabelecer uma ligação entre os atos de rebeldia e as leis que vão sendo regulamentadas após o fim do tráfico, 
como a Lei do Ventre Livre. Se estas leis podem ser vistas como uma vitória da classe senhorial, no sentido de ter conseguido adiar ao máximo a extinção da escravatura, elas também devem ser percebidas como uma conquista dos escravos, resultado da pressão manifestada a atuação política dos cativos.

O aprofundamento destas hipóteses contribuirá para desmistificar uma série de equívocos e falsas idéias que até agora vigoram em boa parte da historiografia onde ao negro se reservou ora o papel de ser submisso, ora de herói. Trata-se de percebê-lo como sujeito histórico que ao longo do desenvolvimento do sistema escravista criou, diante de suas condições de existência concreta, estratégias cotidianas de luta. $\mathrm{O}$ escravo lutou o quanto pode não só através de atos ilegais, mas também dentro dos espaços legais abertos pelo sistema, para fugir à dominação e exploração aos quais estava submetido tentando melhorar seu nível de vida. E o estudo pretende resgatar também outras formas de luta desenvolvidas pelo escravo no seu dia-a-dia, como negociações e acordos sem apelar para atitudes radicais, e que muitas vezes são interpretadas como "submissão", mas que na realidade não significam "ausência de luta, mas uma estratégia sob condições extremamente desfavoráveis". ${ }^{28}$

O fato da escravidão ter sito extinta pela dinastia de Bragança e todo o processo controlado e dirigido pelas elites políticas dominantes, fez com que muitos autores desconsiderassem a atuação dos escravos neste processo, pois introjetaram a visão do branco vencedor, gerando sem dúvida, uma percepção distorcida daquela realidade, porque unilateral. Idéias como a docilidade da escravidão, a submissão constante do escravo, a tutela sempre presente do branco, seja na concessão da alforria, seja na sobrevivência do cativo, contribruíram para a manutenção de uma ideologia que atendia aos interesses dos proprietários escravistas do século XIX, e que ainda hoje continuam a atender os interesses das classes dominantes, na medida em que se preserva a idéia do conformismo e da passividade do "brasileiro", negando os conflitos classistas verificados na sociedade na qual o negro continua ocupar posições de inferioridade - seja profissionalmente, seja sofrendo discriminação racial. 


\section{Notas}

1. Agradecemos ao FIP (Fundo de Incetivo à Pesquisa) da PUCMG o financiamento da pesquisa.

2. Os jornais estão classificados na seção đe "Jornais Avulsus" do Arquivo Público Mineiro e perfazem um total de 70 títulos de diversas tendências: Conservadores, Liberais, Abolicionistas e Republicanos.

3. Segundo Robert Conrad, "apesar đa melhoria das condiçб̃es depois de meados do século, os escravos no Brasil foram incapazes, até mesmo durante as últimas décadas de escraviđão, de manter seus números através de meios naturais". Os Úlitimos Anos da Escravatura no Brasil: 1850-1888. Rio de Janeiro, Civilizaçăo Brasileira, INL, 1975. p.36. Entretanto, para Douglas Cole Libby, no período pós-1850, existem evidéncias (embora os dados sejam escassos) de "um aumento na capacidade de reprodução da população cativa" na província de Minas Gerais em funçã̃o da "maior preocupação entre os senhores de escravos em melhorar o tratamento dado aos cativos exatamente no sentido de proteger e fazer crescer seus investimentos face à reduzida oferta de 'peças de reposição' ". Transformação e Trabalho em uma Economia Escravista. Minas Gerais no século XIX. São Paulo, Brasiliense, 1988. p.61.

4. GEBARA, Ademir. "Escravidão: Fugas e Controle Social". In: Estudos Econômicos. São Paulo, 18(103-146):101, 1988.

5. Segundo Ademir Gebara, com o qual concordamos, "a lei não pode ser estuđada como um fenômeno passivo, que existe apenas como uma mera conseqüência de uma dada formação social. A lei constitui uma força ativa na mediação entre as classes, sendo também uma força parcialmente autônoma, na qual as reivindicaçőes dos dominados devem ser, necessariamente acomodadas". O Mercado de Trabalho Livre no Brasil. São Paulo, Brasiliense, 1986. p.12.

6. Segundo José Pedro Xavier da Veiga, no ano de 1888 existiam aproximadamente 800.000 escravos no Brasil, dos quais 230.000 se concentravam nas Minas. Efemérides Mineiras (1664-1897). Ouro Preto, Imprensa Oficial, 1987. p.428. Trabalhando com mapas de população đo século XIX, Douglas Cole Libby aponta 367.443 escravos em Minas (18,2\% do total geral no Brasil), segundo o Resenceamento de 1872. Op. cit. p.53.

7. LIBBY, Douglas C. Op. cit. p.346-50.

8. CAPELATO, Maria Helena R. Imprensa e História do Brasil, São Paulo, Contexto, 1988. p.13.

9. Idem, Ibidem, p.24.

10. SCHWARCZ, Lilia Moritz. Retrato em Branco e Negro. Jornais, escravos e cidadãos em São Paulo no final do século XIX. São Paulo, Companhia das Letras, 1987, p.17.

11. GINZBURG, Carlo. "Morelli, Freud e Sherloch Holmes: Pistas e o Método Científico". History Worshop Journal. 9, 1980. Trad. de Francisco A.S. Grossi. p.22.

12. Ressaltamos o trabalho de Oliam José, único trabalho específico sobre a abolição em Minas, Belo Horizonte, Itatiaia, s/d. Nāo obstante considerar a rebeldia negra fator de desestruturação do sistema, o autor compartilha da idéia da docilidade da escravidão. Sua visão do processo abolicionista mineiro é superficial, embora não se possa negar a importância do estudo ainda que pouco verticalizado.

13. LARA, Silvia H. - "Trabalhadores Escravos". In: Trabalhadores Escravos, Campinas, Unibanco, 1989. p.18.

14. Entendemos, conforme Thompson, classe social como um "fenômeno histórico" e não uma mera classificaçăo; ou seja, na trajetória de inúmeras lutas travadas no tempo histórico, determinados homens ao vivenciarem e compartilharem experiências comuns sentem e identificam seus interesses contrapondo-se, desta forma, a outros grupos de homens cujos interesses são diferentes e mesmo antagônicos aos seus. 